\title{
Inframarginal Economics
}




\section{Increasing Returns and Inframarginal Economics}

ISSN: 1793-0960

Series Editors: James Buchanan

Yew-Kwang Ng, (Xiaokai Yang)

Guang-Zhen Sun

Published

Vol. 1 An Inframarginal Approach to Trade Theory

Edited by Xiaokai Yang, Wenli Cheng, Heling Shi \&

Christis G. Tombazos

Vol. 2 Readings in the Economics of the Division of Labor: The Classical Tradition

Edited by Guang-Zhen Sun

Vol. 3 Inframarginal Contributions to Development Economics Edited by Christis Tombazos \& Xiaokai Yang

Vol. 4 Inframarginal Economics

Edited by Xiaokai Yang \& Wai-Man Liu

Forthcoming

Inframarginal Analysis of Economic Development and Globalization by He-Ling Shi \& Xiaokai Yang 
Increasing Returns and Inframarginal Economics - Vol. 4

\section{Inframarginal Economics}
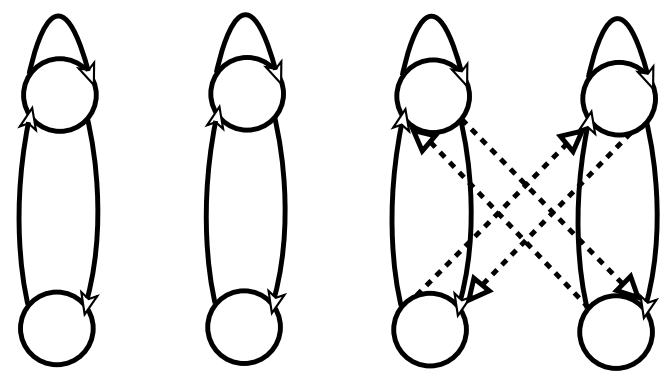

\section{Xiaokai Yang Wai-Man Liu}

University of New South Wales, Australia 


\section{Published by}

World Scientific Publishing Co. Pte. Ltd.

5 Toh Tuck Link, Singapore 596224

USA office: 27 Warren Street, Suite 401-402, Hackensack, NJ 07601

UK office: 57 Shelton Street, Covent Garden, London WC2H 9HE

\section{British Library Cataloguing-in-Publication Data}

A catalogue record for this book is available from the British Library.

\section{INFRAMARGINAL ECONOMICS \\ Increasing Returns and Inframarginal Economics - Vol. 4}

Copyright () 2009 by World Scientific Publishing Co. Pte. Ltd.

All rights reserved. This book, or parts thereof, may not be reproduced in any form or by any means, electronic or mechanical, including photocopying, recording or any information storage and retrieval system now known or to be invented, without written permission from the Publisher.

For photocopying of material in this volume, please pay a copying fee through the Copyright Clearance Center, Inc., 222 Rosewood Drive, Danvers, MA 01923, USA. In this case permission to photocopy is not required from the publisher.

ISBN-13 978-981-238-928-2

ISBN-10 981-238-928-8

Printed in Singapore. 
This book is dedicated to the memory of Professor Xiaokai Yang, who passed away during the preparation of this manuscript. His teaching, uncompromising integrity and dedication to the research of Inframarginal Economics will be dearly missed by all. 
This page intentionally left blank 


\section{Preface}

This book provides systematic and comprehensive materials for applying inframarginal analysis to the study of a wide range of economic phenomena. The analysis is based on a new overarching framework known as the "Smithian framework", pioneered by Yang (1988) and Yang and $\mathrm{Ng}$ (1993). The framework is employed to resurrect the classical notion of division of labor and specialization which is the essential source of increasing nation's wealth.

This framework has many conceptual and policy implications different from those of orthodox analysis. It differs from Marshall's marginal analysis of demand and supply which is based on the neoclassical dichotomy between pure consumers and firms and separates the analysis of demand and supply from the analysis of individuals' decisions in choosing their levels of specialization. The framework begins from an analysis of individual consumer-producers' decisions in choosing levels of specialization, and then applies inframarginal analysis (total benefit-cost analysis across corner solutions in addition to marginal analysis of each corner solution) to investigate how the network size of division of labor in society is determined in the market place. According to this inframarginal analysis, demand and supply are two sides of the division of labor (Allyn Young, 1928). Hence demand and supply are determined not only by resource allocation for a given network pattern of division of labor, but also by the network pattern of division of labor.

Under this framework, we do not have a dichotomy between microeconomics and macroeconomics. Since a particular level of division of labor is associated with a certain size of market network, the extent of the market and aggregate demand are determined by individuals' decisions 
in choosing their levels of specialization that yield the network size of division of labor for society as a whole. Hence many macroeconomic phenomena, such as unemployment and business cycles are some special features of the complicated network of division of labor.

In this book, non-linear programming, dynamic programming, and other nonclassical mathematical programming are employed to resurrect the spirit of classical mainstream economics within a modern body of formalism. Despite the innovation, it keeps the continuity of the mainstream of economics through a synthesis of the existing and emerging branches of economics. Neoclassical trade theory is synthesized into the text by highlighting its features of inframarginal comparative statics that generate jumps of equilibrium trade pattern across corner and interior solutions (chapter 10). New trade theory developed by Dixit and Stiglitz (1977), Krugman (1979, 1980, 1981), Ethier (1982), and others is covered in chapter 9. New equilibrium game models such as the models of Nash bargaining game and Rubenstain's alternating offer bargaining game and the model of commitment game of Dewatripont-Maskin, are covered and applied to analyze the relationship between endogenous transaction costs and network size of division of labor in chapters 7 and 8 .

New models that formalize the notion of endogenous transaction costs caused by moral hazard and information asymmetry, the theory on structure of residual rights and incomplete contract, and the new theory of the firm are covered in chapters 7 and 8. These models are extended in this text to explore the relationship between endogenous transaction costs, evolution of division of labor, structure of property rights, and emergence of the institution of the firm. New endogenous growth models (AK models, R\&D based models, and models with endogenous evolution of division of labor) are covered in chapters 18, 19, and 20. The different endogenous growth models are compared in the light of recent empirical work that tests them against observations.

Several Smithian general equilibrium models are used to develop an overarching framework for explaining all micro and macro phenomena. It is shown that when the network size of division of labor is endogenized in a general equilibrium analysis, marginal comparative statics for a given pattern of the network can address conventional 
microeconomic resource allocation problem, while inframarginal comparative statics explain discontinuous jumps of the equilibrium size of network of division of labor and related aggregate variables across different structures. The inframarginal comparative statics (or dynamics) can then explain emergence of money, business cycles, and unemployment from division of labor. Hence, for our grand synthesis, macroeconomic analysis and microeconomic analysis are just at two different levels within an integrated framework.

Many insights of Buchanan, Cheung, Coase, and North into transaction costs, property rights, institution of the firm, and contract are formalized in the text. Challenges posed by nonlinear evolutionary economics (see Nelson, 1995, Conlisk, 1996, and references therein) and by the Austrian School (see Kirner, 1997, and references therein) against the mainstream are taken and absorbed into the text. For instance, the concept of Walrasian sequential equilibrium is developed in chapter 20 to predict concurrent evolution of economic organisms and evolution of information acquired by society through social experiment with various organisms using price mechanism. The recursive paradox, which means that a decision problem based on bounded rationality cannot be well defined, raised by nonlinear evolutionary economists is solved in a well closed dynamic general equilibrium model based on adaptive behaviors and bounded rationality. The dynamic equilibrium model substantiates the proposition in nonlinear evolutionary economics that concurrent evolution of organisms and information about organisms acquired by society involves uncertainty of the direction of the evolution as well as a certain tendency of the evolution (Nelson, 1995).

We are greatly indebted to our coauthors of various research papers which are covered in this text: Jeff Borland, Been-Lon Chen, Wen-Li Cheng, Chih-Ning Chu, Ben Heijdra, Geoff Hogbin, Ke Li, Chien-fu Lin, Monchi Lio, Mong-Chun Liu, Pak-Wai Liu, Siang Ng, Yew-Kwang Ng, Babu Nahata, Bob Rice, Jeff Sachs, He-Ling Shi, Guangzhen Sun, Ian Wills, Jianguo Wang, Kar-yiu Wong, Shuntian Yao, Dingsheng Zhang, Yiming Zhao, Lin Zhou. We have benefited immensely from comments and criticisms on research papers and books that relate to this text from Ken Arrow, Gary Becker, Avner Ben-Ner, Fischer Black, James Buchanan, Steven Cheung, Cyrus Chu, Eric van Damme, Herbert Dawid, Jurgen 
Eichberger, Karl Farmer, John Gallup, Robert Gilles, Oliver Hart, Heinz Kurz, Lachie McGregor, Eric Maskin, Paul Milgrom, Douglas North, Lloyd Reynolds, Peter Ruys, Andrei Shleifer, Hugo Sonnenschein, Sherwin Rosen, Donald Smythe, Willy Spanjers, Guoqiang Tian, Andrew Warner, Chenggang $\mathrm{Xu}$, Gang Yi, Weiying Zhang, and participants of numerous seminars and conference sessions.

We gratefully acknowledge the financial support for this project and related research from the Center for International Development at Harvard University, Australian Research Council, Chinese University of Hong Kong, National Taiwan University, Institute of Economics of Academia of Sinica, the National Sciences Council of the Republic of China, China Economic Guanghua School of Management, Peking University, University of New South Wales, Centre for Increasing Returns and Economic Organization at Monash University and Centre for Economic Research at Tilburg University.

Any remaining errors are solely our own responsibility.

Xiaokai Yang Wai-Man Liu 


\section{Contents}

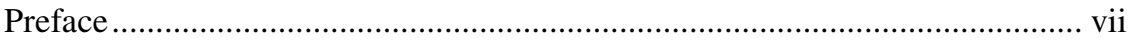

$\begin{array}{ll}\text { Chapter 1: Introduction } & 1\end{array}$

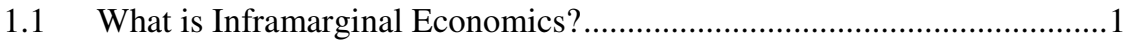

1.2 Economic Analysis of Division of Labor - A Literature Review ................3

1.3 Inframarginal Economics vs. Neoclassical Economics .............................14

1.4 Inframarginal Analysis of Division of Labor..........................................20

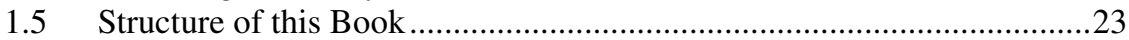

PART I: BASIC MODELS IN INFRAMARGINAL ECONOMICS 31

Chapter 2: Consumer-producer's Decisions to Choose the Optimum Level and Pattern of Specialization 31

2.1 The Smithian Framework and Transaction Costs .....................................31

2.2 Configurations and Corner Solutions in the Smithian Framework ............34

2.3 The Optimum Resource Allocation for a Given Level and Pattern of

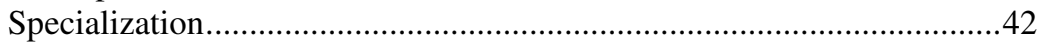

2.4 The Optimum Level and Pattern of Specialization ................................48

2.4.1 Inframarginal analysis of demand and supply ...........................48

2.4.2 Inframarginal and marginal comparative statics of the

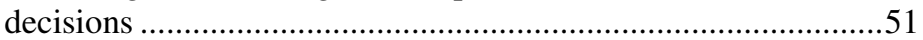

2.5 Neoclassical and Smithian Laws of Supply and Elasticity of

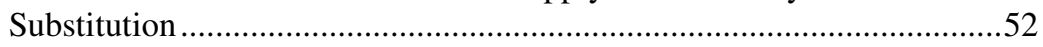

Chapter 3: Smithian General Equilibrium and Its Welfare Implications 59

3.1 Neoclassical vs. Smithian General Equilibrium .....................................59 
3.2 How Does the Market Coordinate the Division of Labor and Utilize Network Effects?

3.2.1 Structure, corner equilibrium, and resource allocation for a given structure of division of labor...

3.2.2 General equilibrium level and structure of division of labor - how does the market coordinate division of labor to utilize network effects.

3.3 Inframarginal Comparative Statics of Smithian General Equilibrium.....72

3.3.1 Inframarginal vs. marginal comparative statics of Smithian general equilibrium

3.3.2 Comparative statics of decisions vs. comparative statics of equilibrium

3.3.3 The inappropriateness of marginal cost pricing and the difference between neoclassical and Smithian general equilibrium

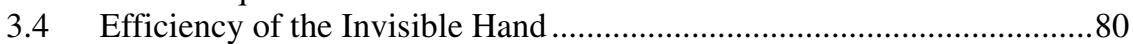

3.4.1 The first welfare theorem in the Smithian framework .................80

3.4.2 Economic development and disparity between the pareto optimum and the PPF

3.4.3 Interdependence and conflict between efficient resource allocation and efficient organization.

4.1 Theoretical Foundation of Inframarginal Economics .............................91

4.2 A General Smithian Model with ex ante Different

Consumer-producers

4.3 The Existence of a Competitive Equilibrium...........................................96

4.4 Equilibrium Organism and Efficiency of the Invisible Hand in Coordinating Division of Labor.

Chapter 5: Trade Pattern and Professional Middlemen

5.1 Why Can the Professional Middleman Make Money? What Are the Determinants of Business Success?

5.2 A Model with Trading Activities and Heterogeneous Parameters..........112

5.3 The Decision to Be a Professional Middleman.......................................114

5.4 Market Structures and Corner Equilibria ...............................................117

5.4.1 Basic vs. nonbasic structures .................................................117

5.4.2 Definitions of corner and general equilibria ..............................119

5.5 The Equilibrium Size of the Network of Division of Labor ...................122

5.6 Emergence of Professional Middlemen and a Hierarchical Structure of Economic Organization. 
PART II: THE INSTITUTION OF THE FIRM AND PRICING THROUGH

BARGAINING AND CONTRACTING

Chapter 6: The Labor Market and the Institution of the Firm

6.1 What is the Institution of the Firm?

6.2 Is It Fair to Have an Asymmetric Relationship between Boss and Employees? - The Story behind the Model

6.3 Emergence of the Firm from the Division of Labor ...............................142

6.3.1 Economies of roundabout production......................................142

6.3.2 The corner equilibria in four structures ................................... 144

6.3.3 General equilibrium structure of transactions and residual rights

6.4 The Distinction Between ex ante and ex post Production Function and the Smithian Analysis of Demand and Supply....

6.5 Economies of Division of Labor, Economies of the Firm, and Coase Theorem

6.6 The Economies of Division of Labor and the Size of Firms..................162

Chapter 7: Pricing Mechanism Based on Bargaining

7.1 Bargaining Game, Strategic Behavior, Opportunistic Behavior ............171

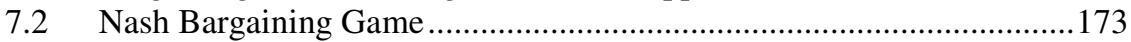

7.3 Endogenous Transaction Costs caused by Information Asymmetry......180

7.4 Alternating Offer Bargaining Games ..................................................183

7.5 Dynamic Bargaining Game and the Division of Labor ........................186

7.6 How Does Competition for a Greater Share of Gains from the Division of Labor Generate Endogenous Transaction Costs? ................189

7.7 How Can Endogenous Transaction Costs be Eliminated by Consideration of Reputation?

7.8 Information Asymmetry, Dynamic Bargaining, and the Division of Labor......

7.9 Non-credible Commitment and Soft Budget Constraint .......................202

Chapter 8: Endogenous Transaction Costs and Theory of Contract, Ownership, and Residual Rights

8.1 Endogenous Transaction Costs and Moral Hazard ................................205

8.2 Neoclassical Principal-Agent Models ................................................208

8.3 A Smithian General Equilibrium Model of Principal-Agent .................214 
8.4 The Trade off Between Endogenous Transaction Costs caused by Moral Hazard and Monitoring Cost and Incomplete Labor Contract ....222

PART III: INFRAMARGINAL ANALYSIS OF TRADE AND GLOBALIZATION

Chapter 9: Emergence of International Trade from Domestic Trade and Emergence of New Products

9.1 Endogenous Trade Theory and Endogenous Number of Consumer Goods

9.2 A Smithian Trade Model with Fixed Learning Costs

9.3 How are Demand and Supply Functions Determined by Individuals' Levels of Specialization?

9.4 Inframarginal Comparative Statics of the Optimum Decisions 248

9.5 How is the Level of Division of Labor in Society Determined in the Market?

9.6 Inframarginal Comparative Statics of General Equilibrium and Many Concurrent Economic Phenomena.

9.7 Emergence of International Trade from Domestic Trade ......................261

9.8 Comovement of Division of Labor and Consumption Variety ...............263

9.9 Trade off Between Economies of Specialization and Coordination Costs

9.10 A Neoclassical Model Endogenizing the Number of Consumption Goods on the Basis of the Trade off Between Economies of Scale and Consumption Variety

9.11 An Extended Murphy-Shleifer-Vishny Model with Compatibility between Economies of Scale and Competitive Market

Chapter 10: Exogenous Comparative Advantages in Technology and Endowment, Division of Labor, and Trade

10.1 Endogenous vs. Exogenous Comparative Advantage 283

10.2 A Ricardian Model with Exogenous Comparative Technological Advantage and Transaction Costs.

10.3 Analysis of Decisions vs. Analysis of Equilibrium ...............................294

10.4 Economic Development and Trade Policy..............................................303

10.5 Comparative Endowment Advantage and Trading efficiency ................314

Chapter 11: Inframarginal Analysis of Coexistence of Endogenous and Exogenous Comparative Advantage

11.1 Implications of the Coexistence of Endogenous and Exogenous Comparative Advantage 
11.2 A Smithian Model with Dual Structure

11.3 Trade Pattern and Income Distribution

Part IV: URbanization, Population, AND the TRADE OFF BETWEen WORKING AND LEISURE

\section{Chapter 12: Urbanization, Dual Structure Between Urban and Rural} Areas, and the Division of Labor

12.1 Why and How Cities Emerge from the Division of Labor?

12.2 Emergence of Cities and of the Dual Structure Between Urban and Rural Areas

12.3 Why Can Geographical Concentration of Transactions Improve Trading Efficiency?

12.4 Simultaneous Endogenization of Level of Division of Labor, Location Pattern of Residences, Geographical Pattern of Transactions, and Land Prices

12.5 A Neoclassical Model of Urbanization based on the Trade off Between Economies of Scale and Transaction Costs

Chapter 13: The Trade off between Working and Leisure, and the Effects of Resource Scarcity and Population Size on the Division of Labor

13.1 Why Can Division of Labor Enlarge the Scope for the Efficient Trade off Between Working and Leisure?

13.2 Why Can Leisure Time and Per Capita Consumption of Each Good Increase as Division of Labor Develops?

13.3 Why Can a Crisis of Resource Shortage Promote Evolution in Division of Labor and Productivity?.

13.4 Implications of High Population Density for Evolution in Division of Labor through Its Effect on the Per Capita Expenditure on Infrastructure.

Chapter 14: Economics of Property Rights and Insurance and Risk of Coordination Failure of the Network of Division of Labor

14.1 Uncertainties in Transactions and the Economics of Property Rights ...411

14.2 Trade offs among Economies of Division of Labor, Coordination Reliability, and Benefits of Competition

14.3 Endogenization of Coordination Reliability in Each Transaction 422

14.3.1 The Yang-Wills model endogenizing risk of coordination failure for each transaction

14.3.2 The efficient extent of externalities 425 
14.3.3 Perfect competition is inefficient ...........................................426

14.3.4 Risk of mass unemployment..........................................428

14.3.6 Economics of property rights and the soft budget constraint....430

14.4 Substitution between Precise Enforcement of Property Rights and

Competition ...........................................................................435

14.5 Uncertainty and Risk Aversion.....................................................443

14.6 A Model with Insurance and Endogenous Specialization in the Absence of Moral Hazard .............................................................445

14.7 The Division of Labor and Endogenous Transaction Costs caused by Complete Insurance

PART V: HIERARCHICAL STRUCTURE OF DIVISION OF LABOR

\section{Chapter 15: The Division of Labor in Roundabout Production and Emergence of New Machines and Related New Technology}

15.1 Smithian vs. Neoclassical Views on the Emergence of New Producer Goods and Related New Technology ....

15.2 A Model with Endogenous Technical Progress, Endogenous

Number of Producer Goods, and Endogenous Specialization 468

15.3 The Efficient Number of Producer Goods and Level of Specialization

15.4 The Corner Equilibria in 9 Structures....

15.5 Concurrent Changes in the Level of Division of Labor, Productivity, and Input Diversity.....

15.6 Ex post Production Function, Emergence of New Machines, and Endogenous Technical Progress

15.7 Changes in Economic Structure and Topological Properties of Economic Organism

15.8 Evolution in the Number of Producer Goods and Economic Development.

\section{Chapter 16: Industrialization and the Division of Labor in Roundabout} Production

16.1 The Features of Industrialization

16.2 A General Equilibrium Model Endogenizing Production

Roundaboutness

16.3 Corner Equilibria and Emergence of New Industry.............................503

16.4 General Equilibrium and Industrialization.........................................508

16.5 Changes in the Income Shares of the Industrial and Agricultural Sectors 
16.6 The Number of Possible Structures of Transactions Increases More Than Proportionally as Division of Labor Evolves in Roundabout Production

\section{Chapter 17: Hierarchical Structure of the Network of Division of} Labor and Related Transactions

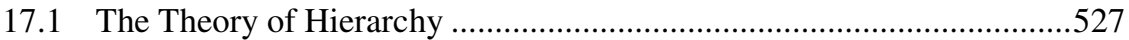

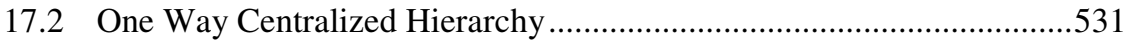

17.3 A Decentralized Hierarchy of Transactions and the Division of Labor.

17.4 Configurations and Market Structures .................................................541

17.5 The General Equilibrium and Its Inframarginal Comparative Statics....550

17.6 Network Hierarchy of Cities and Division of Labor. 553

17.6.1 Consumer-producers, cities, and layers of a hierarchy of cities

17.6.2 Two types of transaction costs................................................556

17.6.3 The optimal number of layers in a hierarchical structure ..........560

PART VI: INFRAMARGINAL ANALYSIS OF ECONOMIC DEVELOPMENT AND

GROWTH

\section{Chapter 18: Economic Growth Generated by Endogenous Evolution in Division of Labor}

18.1 Economies of Specialized Learning by Doing and Endogenous Evolution in Division of Labor

18.2 A Smithian Dynamic Model with Learning by Doing ............................570

18.3 Optimum Speed of Learning by Doing and Evolution of Endogenous Comparative Advantage ...............................................572

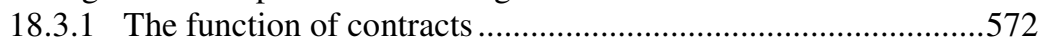

18.3.2 An individual's dynamic decision problem ..............................574

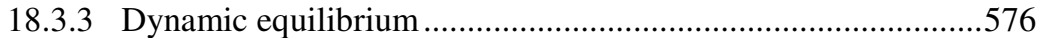

18.4 Endogenous Evolution of the Extent of the Market, Trade

Dependence, Endogenous Comparative Advantages, and Economic

Structure.

18.5 Empirical Evidences and Rethinking Development Economics and Endogenous Growth Theory

Appendix 18.1: The Relationship between the Control Theory and 
Chapter 19: Concurrent Endogenous Evolution in Division of Labor, in the Number of Goods, and in the Institution of the Firm

19.1 How Can We Simultaneously Endogenize Evolution in Division of Labor and in the Number of Producer Goods?

19.2 A Dynamic Equilibrium Model with Learning by Doing and an Endogenous Number of Producer Goods.

19.3 Dynamic Equilibrium Level of Specialization and Input Variety.....

19.4 Concurrent Evolution of Specialization, Variety of Producer Goods, and the Institution of the Firm

Appendix 19.1: Proof of Lemma 19.1

Appendix 19.2: Proof of Proposition 19.1

Appendix 19.3: Proof of Proposition 19.2.

Chapter 20: Experiments with Structures of Division of Labor and Evolution in Organization Information Acquired by Society

20.1 How Does Organization Knowledge Acquired by Society

Determine Economic Development?

20.2 A Static Model with Endogenous Length of Roundabout

Production Chain and Endogenous Division of Labor

20.3 Interactions Between Dynamic Decisions and Evolution in Organization Information

20.4 Walrasian Sequential Equilibrium and Concurrent Evolution in Organization Information and Division of Labor.

PART VII: MACROECONOMIC PHENOMENA AND ENDOGENOUS SizE OF NETWORK OF DIVISION OF LABOR

Chapter 21: Theory of Investment and Saving

21.1 Neoclassical Theory of Investment and Saving ...................................673

21.2 Neoclassical Models of Self-Saving and Interpersonal Loans ...............679

21.3 Smithian Theory of Investment and Savings ..........................................685

21.3.1 Configuration sequence and structure sequence........................687

21.3.2 Dynamic corner equilibria in 16 structure sequences.................690

21.4 Investment, Capital, and Division of Labor in Roundabout

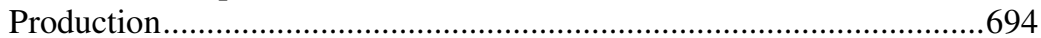

21.4.1 Dynamic general equilibrium ................................................695

21.4.2 Non-topological properties of economic growth and sudden decline of interest rates.

21.4.3 Endogenous decision horizon and effect of liberalization reforms on opportunities for lucrative investment. 
22.1 Neoclassical vs. Smithian Theories of Money ........................................709

22.2 A Smithian Model of Endogenous Monetary Regime ............................714

22.3 Possible Structures and Monetary Regimes............................................716

Chapter 23: Smithian Theory of Business Cycles and Unemployment 731

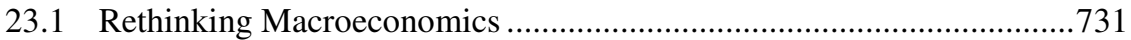

23.2 Long-run Regular Efficient Business Cycles, Cyclical Unemployment, Long-run Economic Growth, and Division of Labor in Producing Durable Goods

23.3 A Smithian Dynamic Equilibrium Model of Business Cycles and Unemployment 747

23.4 Cyclical vs. Non-cyclical Corner Equilibria .....................................750

23.4.1 Regime specification, configurations and market structures ....750

23.4.2 The dynamic corner equilibrium in autarky............................751

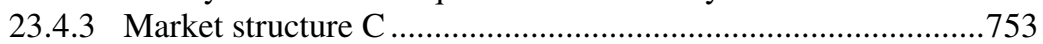

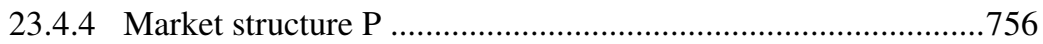

23.4.5 Welfare and policy implications of the model ..........................760

23.5 General Price Level, Business Cycles, and Unemployment Rate...........761

23.6 Emergence of Firms and Fiat Money from the Division of Labor..........765

23.7 Mass Unemployment and the Stability of the Network of Division of

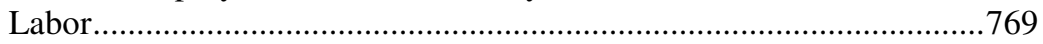

Chapter 24: Effects of Monetary and Fiscal Policies on the Network Size of Division of Labor

24.1 The Role of Infrastructure Expenditure, Monetary and Fiscal Policies on the Evolution of Division of Labor ....................................779

24.2 Infrastructure Expenditure and the Evolution of Division of Labor .......784

24.3 Macroeconomic Policies and the Evolution of Division of Labor..........795

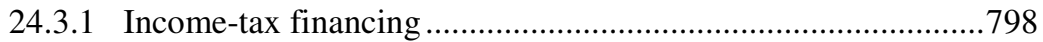

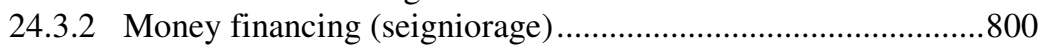

24.3.3 Income-tax financing versus money financing .........................802 
PART VIII: Political ECONOMICS, THE ECONOMICS OF THE STATE, NEW ECONOMY, AND ENDOGENOUS NETWORK SIZE OF DIVISION OF LABOR

Chapter 25: Inframarginal Analysis of Political Economy

25.1 Inframarginal Analysis, Endogenous Transaction Cost caused by Externality, New Institutional Economics, and Smithian Models of

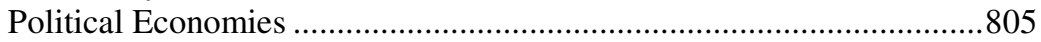

25.2 Inframarginal Analysis of the Evolution of the State.....

25.3 Inframarginal Analysis of Effects of Political Monopoly on the Extent of the Market

Chapter 26: Inframarginal Analysis of e-Business and Franchising

26.1 Impersonal Networking Decisions, Franchising Networks and e-Business

26.2 A Smithian Model of Product Bundling

26.3 A Smithian Model of Franchising Networks .841

Bibliography 851

Index .891 